\title{
THE STRUCTURE OF DUNBARIA
} (PALAEODICTYOPTERA)*

\author{
By Jarmila Kukalová-Peck \\ Department of Geology, Carleton University, \\ Ottawa, Ontario, Canada
}

The extinct order Palaeodictyoptera is the most abundant paleopterous group of insects found in Paleozoic deposits. During its geological range, from the Upper Carboniferous (Namurian) to the Permian (Leonard), the order radiated into extremely diverse lines with adaptations to many environments and with various specializations. In contrast to this speciation, fossils are relatively scarce in spite of their wide distribution. Furthermore, the aerial way of life virtually eliminates the finding of specimens deposited in assemblages of their original and natural communities. These circumstances have greatly reduced the chances of collecting many specimens belonging to one species, with the result that there are almost no data available for intraspecific variations in size, wing venation, and especially secondary sexual characters.

The single exception to this is the case of Dunbaria fasciipennis Tillyard (Spilapteridae) from Permian (Leonard) deposits of Elmo, Kansas. Tillyard based his original description of this species (1924) on three specimens; later (1925) he discussed another three specimens and dealt with the wing venation (in the light of Lameere's venational concepts) and with the terminal abdominal appendages. All six specimens are in the collection of the Peabody Museum, Yale University, and are numbered as follows: holotype IOOI ab, allotype $1002 \mathrm{ab}$, paratype 1050, and specimens 5020, 5021 and 5022. ${ }^{1}$

During my stay at Harvard University in 1968, Professor Carpenter encouraged me to review all of the specimens of fasciipennis and he placed at my disposal three more specimens from his collection in the Museum of Comparative Zoology, Harvard University, numbered $3056 \mathrm{ab}, 3057 \mathrm{ab}$, and 3058 . This series of nine specimens is

\footnotetext{
*This research has been aided by grant number GB-7308 and number GB-27333 from the National Science Foundation (F. M. Carpenter, principal investigator, Harvard University).

${ }^{1}$ Specimen number 5020 in the Peabody Museum was designated by Tillyard in 1925 (page 335) as a paratype of fasciipennis. However, since this particular specimen was not mentioned or even seen by Tillyard at the time of his original description of the species (1924), it has no status as a paratype.
} 
the most extensive aggregation of Palaeodictyoptera belonging to one species so far known.

To avoid confusion, I will first of all discuss several misinterpretations of morphological features included in Tillyard's two papers. With respect to the wings, Tillyard (1924, p. 205; 1925, p. 329) mentions the presence of a very delicate archedictyon extending over the wings. I have been unable to see any traces of this in the fossils. The wing membrane is very thin and is delicately wrinkled in several of the specimens, probably as a result of the process of preservation; I suspect that this wrinkling was interpreted by Tillyard as the archedictyon. A series of strong macrotrichia was described by Tillyard as being present on R, RI, and basal part of Rs, but I find that these macrotrichia are present on all veins, not just these few. With respect to the thorax, Tillyard (1924, p. 203, 205) describes the prothorax as being very short and as lacking prothoracic, lateral lobes. Actually, as shown especially well by specimen $3057 \mathrm{MCZ}$, the prothorax is of normal length for the Palaeodictyoptera and it possesses a pair of sclerotized, prothoracic lobes. In specimen 1002 of the Peabody Museum, which was studied by Tillyard, there is a small fragment of a wrinkled prothoracic lobe, but this was interpreted as the head (Tillyard, 1924, p. 205) and the remnant of the prothorax was considered its full length. So far, no representatives of Palaeodictyoptera have been found without prothoracic lobes. In highly modified species, the lobes may be reduced in size and sclerotized, forming scale-like structures, as in Homaloneura lehmani Kukalová (1969, p. 182, fig. 8) belonging to the family Spilapteridae.

With respect to the abdomen, Tillyard (1924, p. 205) mentioned ten visible segments but actually the eleventh vestigial segment is also present. Subsequently (1924, p. 207), Tillyard implied that males in the Palaeodictyoptera might not have the long cerci; however, such cerci appear to be present in both sexes. The holotype (Peabody Museum IOOI) was considered by Tillyard to be a male, because of having a narrower abdomen than the "female" (no. IOO2) ( 1924, p. 207). However, the lateral edges of all abdominal tergites in the holotype are broken off so that their widths are not measurable. Since the genital structures are not preserved in the fossil, the holotype does not provide any information about its sex. Specimen IOO2, with the complete abdomen and terminal appendages, was described by Tillyard as a female (1924, p. 207; 1925, p. 334, fig. 3). Tillyard's conclusion was based on a misinterpretation of the male claspers, which he thought were the ovipositor; this is discussed more 

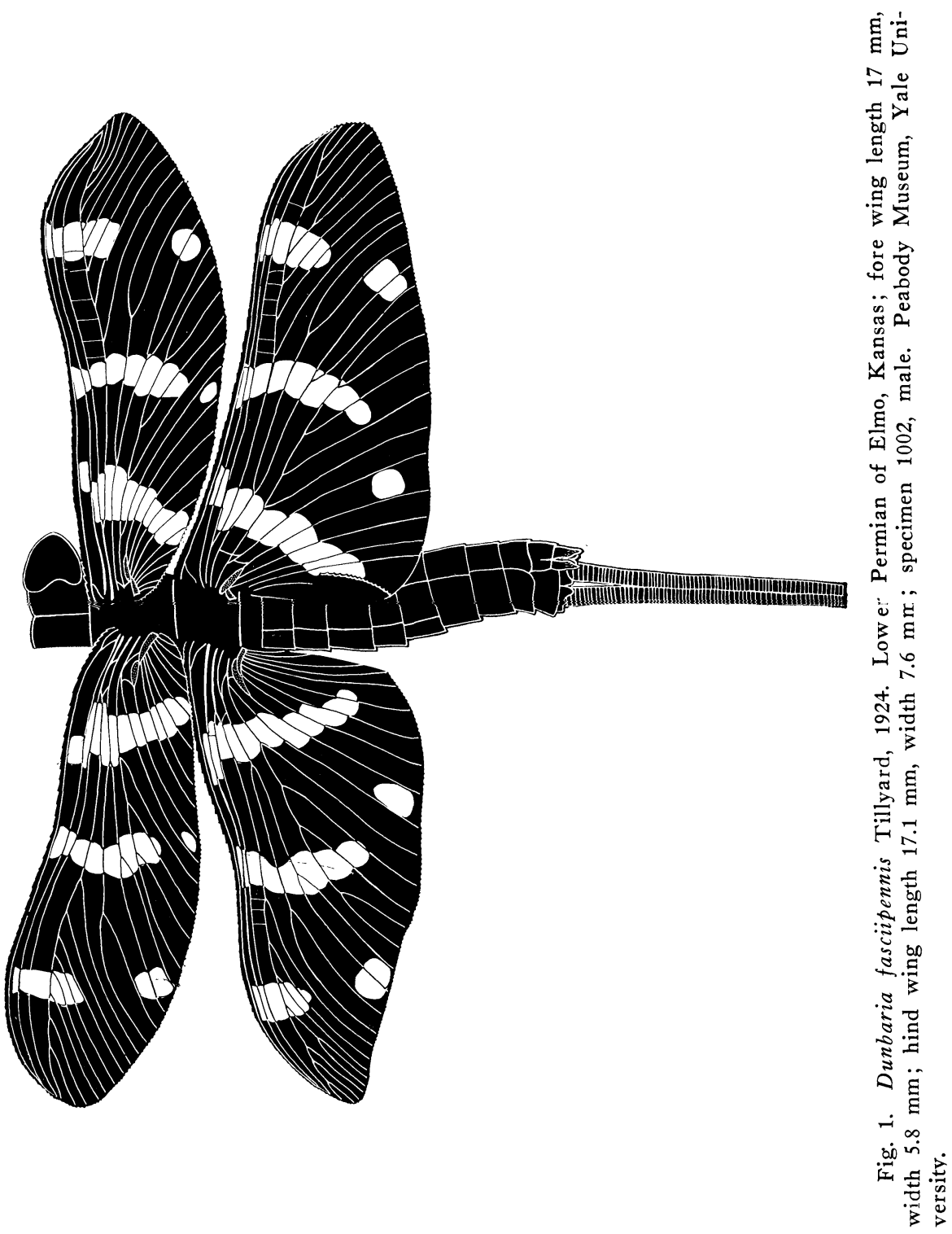

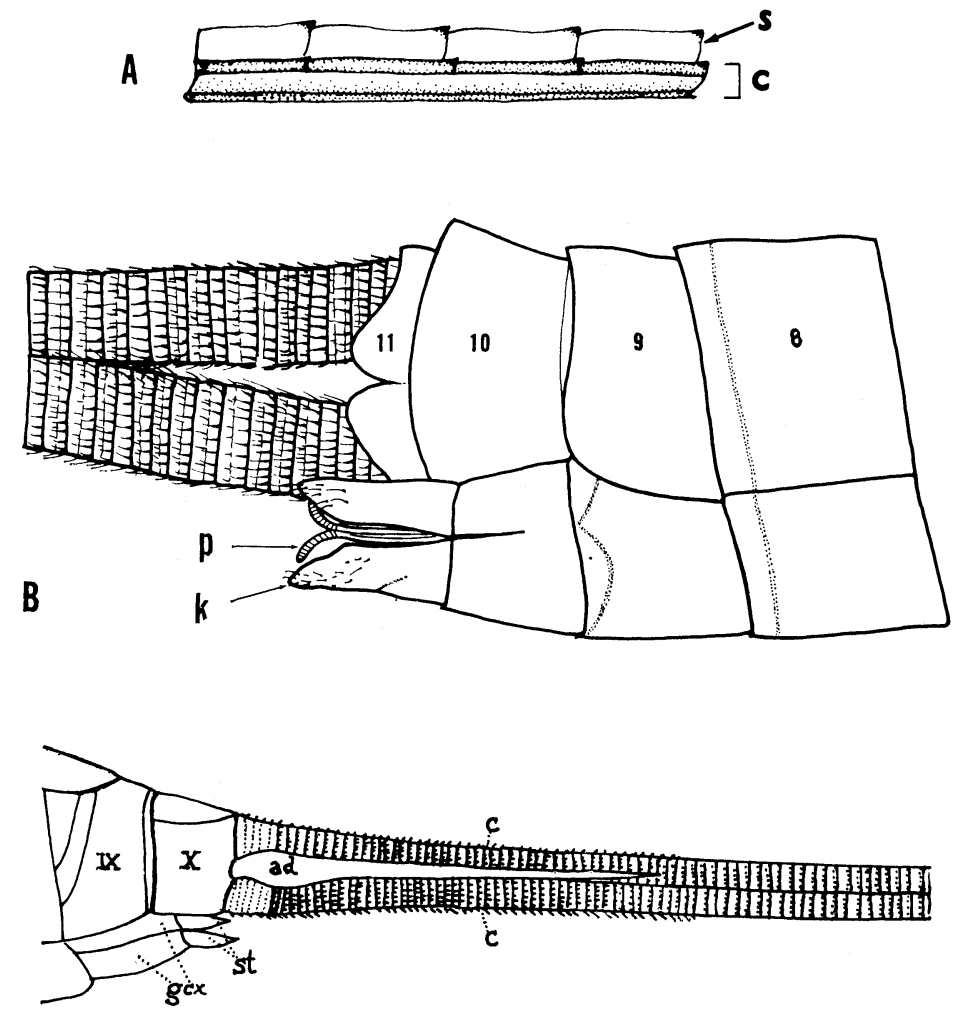

C

Fig. 2-A. Dunbaria fasciipennis Tillyard, 1924, detail of anterior margin in proximal half of the wing; $\mathrm{S}$ - serrated precostal strip; $\mathrm{C}$-broadened band-like costa with serrated anterior ridge.

2-B. Specimen 1002, enlarged end of the abdomen; $\mathrm{K}$-male claspers; $\mathbf{P}-$ slender appendages, with striations, probably parameres.

2-C. The same specimen 1002, enlarged end of the abdomen, after Tillyard (1925, fig. 3 ) ; ad-appendix dorsalis; c-cercus; gcx - gonocoxite; st - style; IX, X - abdominal segments. Peabody Museum, Yale University. 

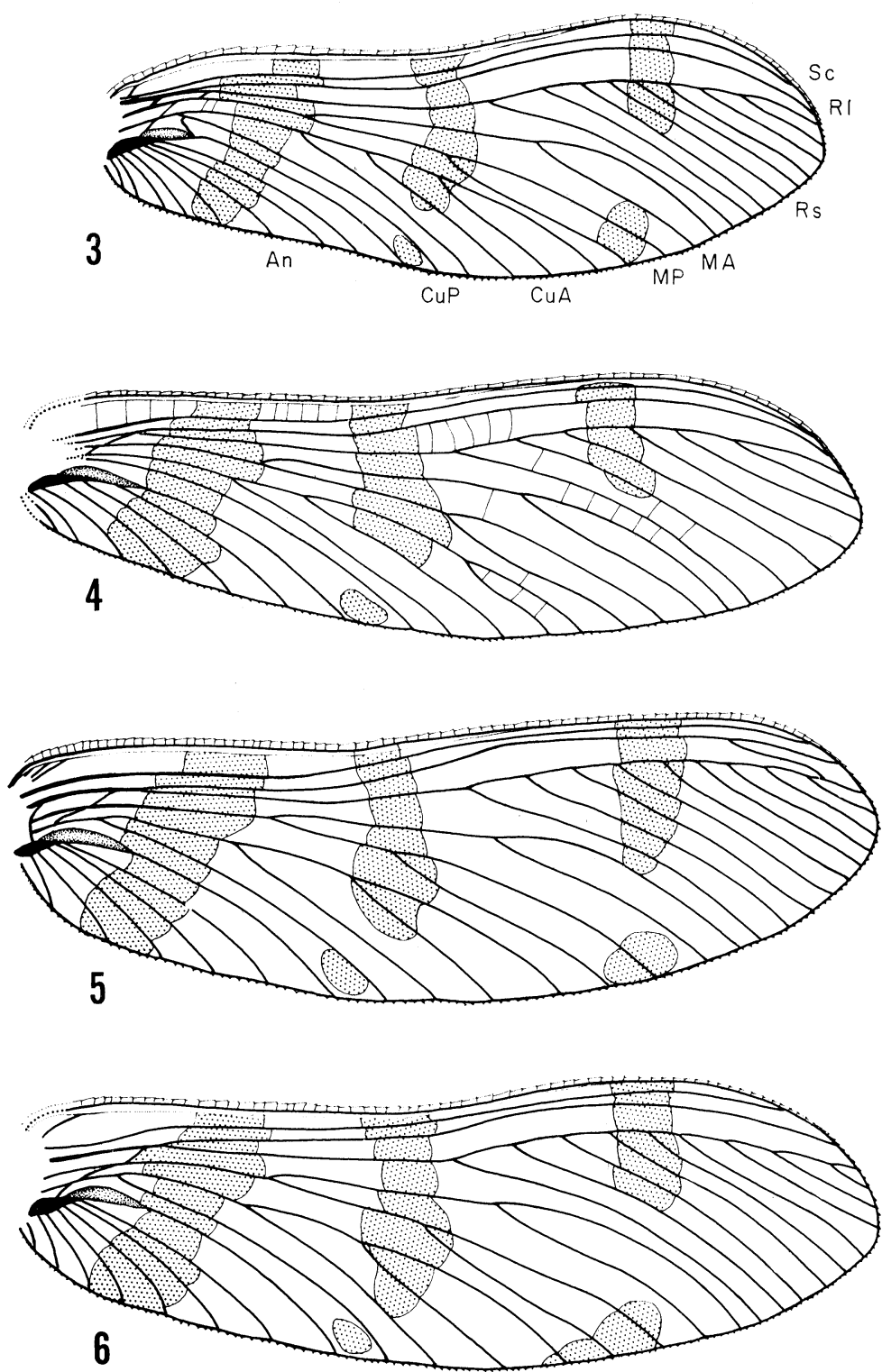

Fig. 3. Specimen 1002. Left fore wing; length $17 \mathrm{~mm}$, width $5.8 \mathrm{~mm}$. Peabody Museum, Yale University.

Fig. 4. Specimen 1050. Left fore wing; length $16.3 \mathrm{~mm}$, width $5.2 \mathrm{~mm}$. Peabody Museum, Yale University.

Fig. 5. Specimen 1001. Holotype. Left fore wing; length $17.2 \mathrm{~mm}$, width $5.5 \mathrm{~mm}$. Peabody Museum, Yale University.

Fig. 6. Specimen 1001. Right fore wing; length $17.2 \mathrm{~mm}$, width $5.5 \mathrm{~mm}$. Peabody Museum, Yale University. 

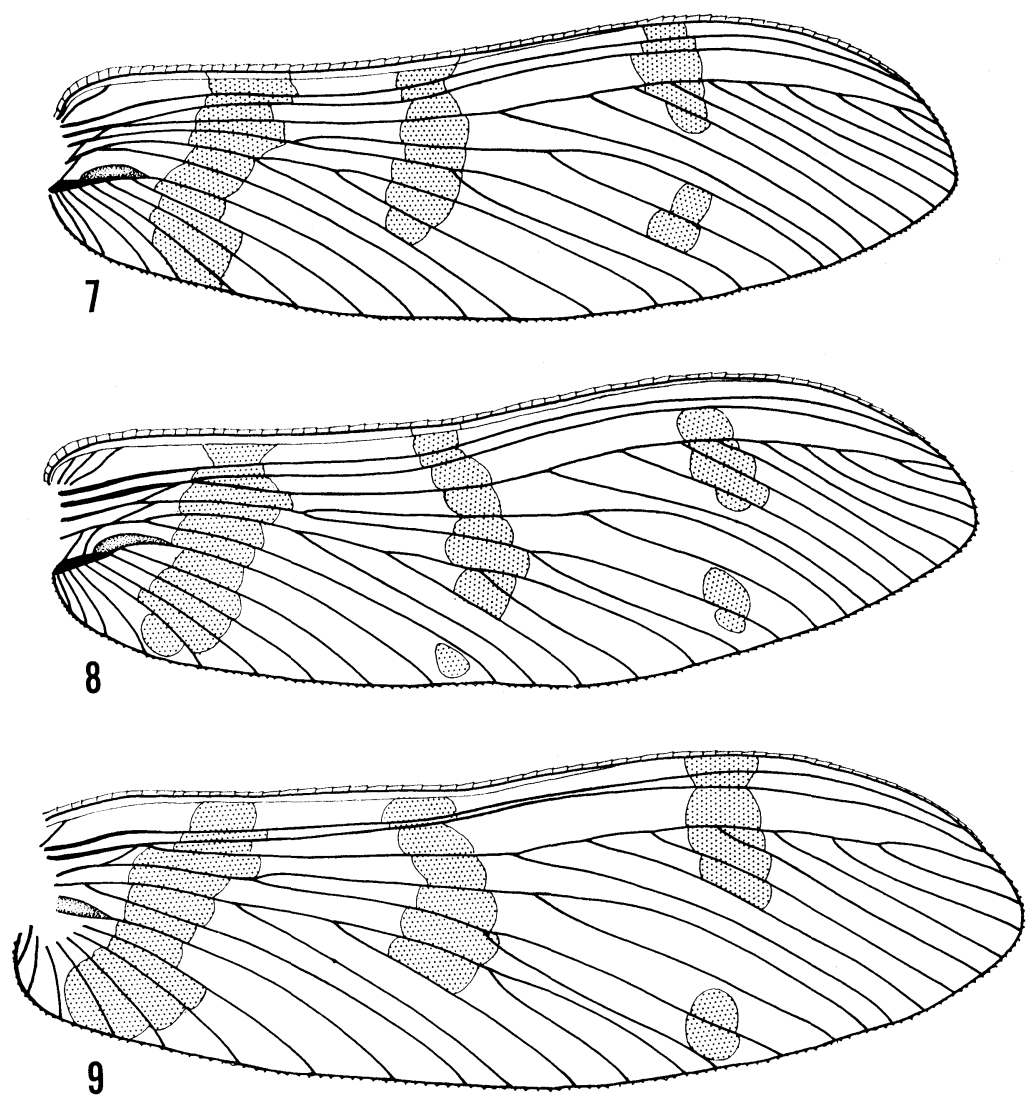

Fig. 7. Specimen 3057. Right fore wing; length $17.8 \mathrm{~mm}$, width $5.5 \mathrm{~mm}$. Museum of Comparative Zoology, Harvard University.

Fig. 8. Specimen 5020. Right fore wing; length $18.1 \mathrm{~mm}$, width $5.4 \mathrm{~mm}$. Peabody Museum, Yale University.

Fig. 9. Specimen 3056. Right fore wing; length $17.3 \mathrm{~mm}$, width $5.3 \mathrm{~mm}$. Museum of Comparative Zoology, Harvard University. 
fully below. Consequently, the nine specimens of Dunbaria fasciipennis do not provide conclusive information about sexual dimorphism.

Mention should also be made of Tillyard's reference to the presence of a "short appendix dorsalis similar to those of some Recent Plectoptera" ( 1925, p. 335, fig. 3). This structure turns out to be a narrow piece of matrix, accidentally included between the cerci of specimen no. IOO2.

\section{New Observations on the Structure of Dunbaria}

Wings: In Palaeodictyoptera with a very delicate wing membrane, additional supporting structures often occur, these being concentrated in the basal third of the wing and along the anterior margin, much as in the wings of the Odonata (Kukalová, I969-I970, Pt. IIII). In the wings of Dunbaria, of which the variation will be discussed later, there are several elements that strengthen the membrane: a series of strong cross veins connect the anal stem to the origin of Rs, supporting the basal third of the wings; the anal stem is unusually wide, flattened and heavily sclerotized; the proximal part of $\mathrm{AI}_{\mathrm{I}}$ is provided with a conspicuous, convex cuticular thickening, apparently also sclerotized; the postcostal area is not flat as in most other Palaeodictyoptera, but forms a triangular, concave fold with I-3 twigs; the precostal strip in both fore and hind wings is serrated, recalling the condition in the Odonata (Tillyard, I924, p. 206) (see fig. 2 A-C) ; the costa is very strong, broadened and band-like in appearance to beyond the middle of the wings, and is provided also by a serrated anterior margin (Fig. $2 \mathrm{~A}-\mathrm{C}$ ). The entire apical and posterior margins are dentate.

The prothoracic paranota are heavily sclerotized, cordate, and covered by dense, short hairs; they do not overlap the fore-wings. Radiating veins are only vaguely indicated in the lobes; the margin is bordered by a thickened ridge. The sclerotization of the paranota is known to be correlated with the reduction of veins in the spilapterid Homaloneura, which is closely related to Dunbaria. The presence of the thickened ridge has already been observed in Eubleptus (Carpenter, 1965, p. I8I, fig. 3) of the closely related family Eubleptidae.

Body Structures: The head is small, eyes prominent; antennae thin, multisegmented, composed of long segments which are slightly broadened distally (fig. I 5) ; thoracic segments almost equal; mesothorax slightly broader than the prothorax and narrower than the metathorax; abdomen relatively slender, composed of I I visible seg- 
ments, the first abdominal segment shorter than the following ones; the eleventh segment vestigial, divided by a deep median incision; cerci originating from the eleventh segment, markedly robust and annulated.

The external genitalia, which are well-preserved in specimen I002, are of special interest. At first sight, they are reminiscent of the valves of an ovipositor and they were interpreted as such by Tillyard ( 1925 , p. 334, fig. 3). This appearance, however, is mostly due to preservation, which must be discussed next.

The abdomen is dorsoventrally flattened in the fossil, but the very end is twisted so that the terminal segments show a lateral view in part. The sternites and the genital appendages are slightly superimposed on the Ioth and IIth tergites. As preserved, the abdomen could be considered comparable to a cylindrical body, flattened by pressure which is directed obliquely to the dorsoventral level, while the under surface of the cylindrical body splits. As a consequence, the genital structures appear more or less in ventral view (fig. $2 \mathrm{~B}$ ).

The genital structures (fig. $2 \mathrm{~B}-\mathrm{K}$ ) are interpreted here as male claspers. They originate at the posterior margin of the 9 th segment, are paired and diverge slightly distally and extend beyond the length of the body. 'They are not sclerotized and their surface is covered with scattered stiff, short hairs that are irregularly distributed and directed posteriorly. Beneath the claspers there is another pair of slender processes, terminating in two thin, posteriorly curved, sclerotized projections; these bear a dense covering of transverse striae. The whole structure resembles the parameres (Fig. 2 B-P) of insects by their position and morphology.

Several features suggest that the processes described above are male structures and not valves of an ovipositor as Tillyard assumed: their general morphology, characteristic attachment to the 9 th sternite, their unsclerotized nature and the presence of posteriorly directed stiff and solitary hairs. These features are contrary to what is known about the ovipositor in Palaeodictyoptera and about ovipositors in general. The female genitalia are known in the family Spilapteridae, to which Dunbaria belongs, in the closely related species Homaloneura ornata Brongniart (Kukalová, I969, p. I79, fig. $7)$; the ovipositor does not differ from that of other Palaeodictyoptera, Megasecoptera and Diaphanopterodea. The valves in all of these related orders are curved, heavily sclerotized and resemble in shape and their broad attachment the valves of some dragonflies (Kukalová, I969, p. 449, fig. 32). If they are provided with hairs, 
the latter are always directed anteriorly. As far as I know, there is no evidence in any insect ovipositor of hairs directed posteriorly, which would presumably prevent the valves from penetrating the substrate.

The male claspers of Palaeodictyoptera have previously been known in only one specimen belonging to Stenodictya spinosa (Brongniart) (Kukalová, I970, Pt. III, p. I I, fig. 53, p. I3, fig. 54). Their structure resembles that of the claspers of Permian Megasecoptera (Carpenter 1939, p. 3I, fig. 2 A) and those of Permian and some Recent Ephemeroptera. They are relatively more primitive, however, composed of small, equal segments, not unlike cerci, and directed towards each other beyond the 9th segment instead of at about the middle. In the light of this evidence, the claspers of Dunbaria may be regarded as very advanced in structure, actually approaching in general respects those of some dragonflies. This circumstance is of great interest, since besides the significant similarity of the female ovipositor to that of dragonflies, Dunbaria provides the first evidence of the similarity of the male genital structures as well. The convergence of wing structures to dragonflies repeatedly occurs in different evolutionary lines of Palaeodictyoptera (Calvertiellidae, Eugereonidae, Archaemegaptilidae, etc.). In spite of the closer relationship which is indicated between the Palaeodictyoptera and Ephemeroptera, all of the evidence, including that of the genitalia, supports the assumption of single ancestral stock of all palaeopterous orders.

\section{Variability of Wings of Dunbaria}

In current studies on palaeodictyopterous wing venation, the secondary branching of veins is generally considered to be not a specific feature but rather one of individual variability. Much emphasis is given by some authors to the level of first branching of main veins, especially $R$ and $M$, and to the widths of wing areas. Little information is known of the individual variability of wing shape and size. The following analysis of wing morphology of nine specimens of Dunbaria fasciipennis provides some data on this subject.

The fore wing length ranges from $16.3 \mathrm{~mm}$ to $18 . \mathrm{Imm}$ and the width from $5.2 \mathrm{~mm}$ to $5.8 \mathrm{~mm}$. The hind wing length varies from I $7 \mathrm{~mm}$ to $17.9 \mathrm{~mm}$ and width from $6.6 \mathrm{~mm}$ to $7.6 \mathrm{~mm}$.

Anterior Margin: It is concavely curved in more or less all wings; this feature in Palaeodictyoptera is often affected by preservation and needs to be considered very carefully. Costa: The bandlike broadening of $\mathrm{C}$ tends to be more pronounced and longer in the larger wings. $S c$ : The length of this vein is variable within the anterior part of 

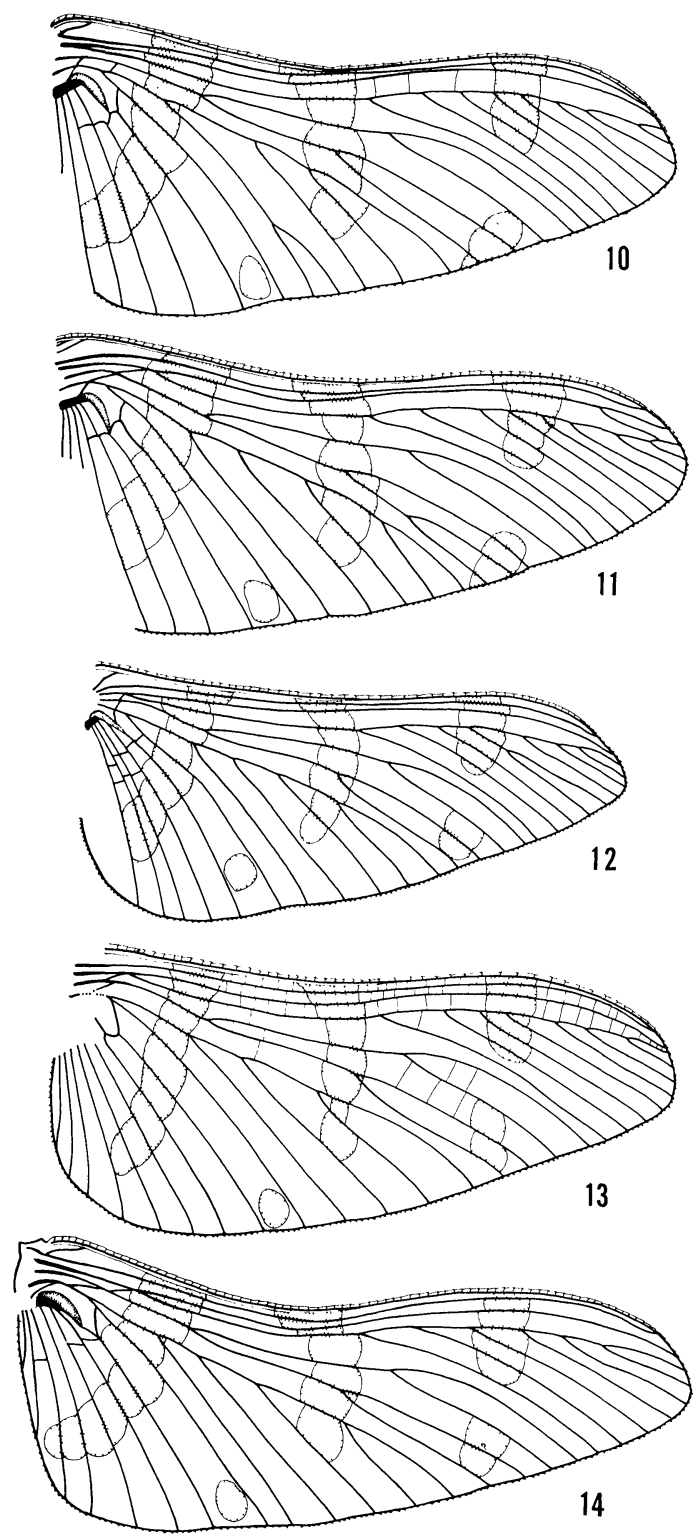

Fig. 10. Specimen 1001. Holotype. Right hind wing; length $17.2 \mathrm{~mm}$, width $7.6 \mathrm{~mm}$. Peabody Museum, Yale University.

Fig. 11. Specimen 1001. Holotype. Left hind wing; length $17.2 \mathrm{~mm}$, width $7.6 \mathrm{~mm}$. Peabody Museum, Yale University.

Fig. 12. Specimen 1002. Right hind wing; length $17 \mathrm{~mm}$, width $7.6 \mathrm{~mm}$. Peabody Museum, Yale University.

Fig. 13. Specimen 5021. Right hind wing; length $17.2 \mathrm{~mm}$, width $7.2 \mathrm{~mm}$. Peabody Museum, Yale University.

Fig. 14. Specimen 3058. Right hind wing; length $17.9 \mathrm{~mm}$, width $6.6 \mathrm{~mm}$, Museum of Comparative Zoology, Harvard University. 
the apical margin; additional terminal branches leading to Rs may occur (specimen IOOI, fore and hind wings). $R s$ : The level of origin of this varies; in extreme cases Rs diverges almost at the very base (specimen IOOI, right hind wing); the number of branches of Rs branches varies in fore wing from 7 to $I O$, in the hind wing from 7 to 9 . Branches of Rs are simple with a single exception (specimen IOO2, 4th branch forked in hind wing). $M$ : It is much alike in all specimens with one exception ( IOOI, left hind wing has an additional twig on MP). Cu: $\mathrm{CuP}$ is always simple, $\mathrm{CuA}$ with 3-4 simple branches in fore wing and with 4-5 simple branches in the hind wing (specimen IOOI has additional twig in the hind wing). An: Anal veins vary from 6 to 9 in the fore wing and from 7 to 8 in the hind wing. Cross veins: The number is very variable; this feature in the Palaeodictyoptera is strongly affected by preservation. Supporting, strong cross veins near the base are highly variable in number and arrangement. Other supporting sclerotized structures at the base (broadened anal stem, cuticular thickening on $A_{I}$ ) are different in size but always present. Wing areas: Postcostal area is highly variable in size and shape, with I-3 twigs. All other areas vary in size and width (e.g., sc-r area). Anal area varies both in length and width, especially in the hind wings. Shape of the wings: This is fairly constant (not considering the secondary deformations of the anterior margin) except for the narrow basal third in the fore wing of the male 1002 and specimen 1050. The posterior margin of the hind wing retains the characteristic undulation. Color pattern: This varies as shown in figures 3-15.

In conclusion, we can say that all of the morphological features in the wings of Dunbaria fasciipennis are variable to some extent, including the level of origin of Rs and the size of the anal area, which may be considered as providing a specific character but not a narrowly defined one. Supporting structures, such as strong cross veins or occasional twigs of main veins, are variable, definitely on an individual level. The outline of the wings presents a rather reliable specific character but the effect of preservation should be thoroughly considered.

Within the 9 specimens of Dunbaria fasciipennis, two fore wings are markedly narrow in the basal third (specimen IOO2 and I050). Since specimen $\mathrm{IOO}_{2}$ is a male, there is a possibility that this feature is a character of sexual dimorphism. This cannot be resolved until more specimens are found with well-pre'erved body parts combined with the wings. 


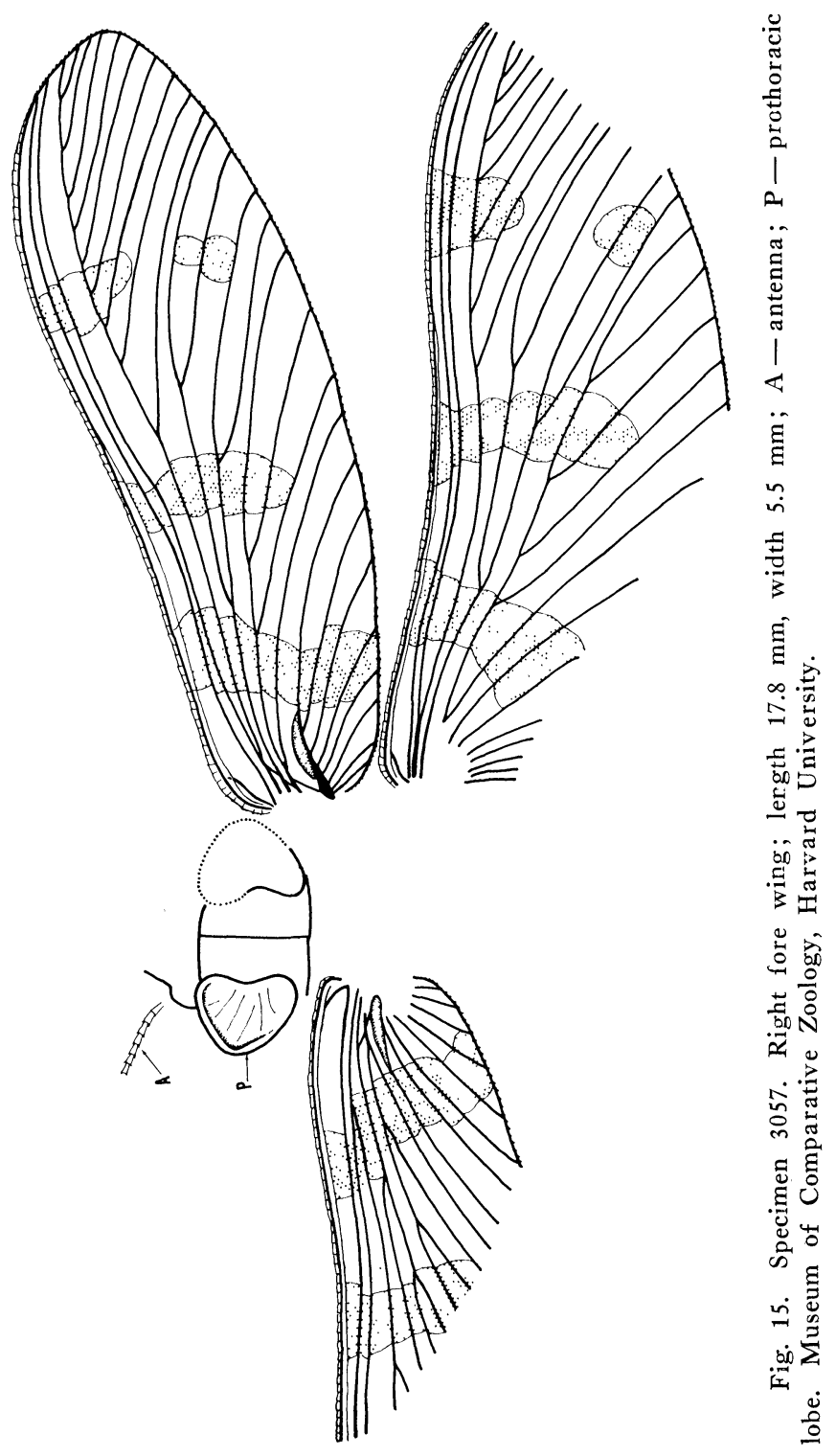


Relationships of Dunbaria. Tillyard ( I924, p. 205) correctly related Dunbaria with another spilapterid genus Homaloneura, occurring in the Upper Carboniferous of Europe and North America (Carpenter, 1964; Kukalová, 1969). Of the species known so far, Homaloneura ornata Brongniart, from the Commentry Shales in France, seems to be the closest. Dunbaria differs in possessing a very long Rs, with more numerous branches and also in possessing a prominent odonate-like serration.

\section{Carpenter, F. M.}

\section{REFERENCES}

1939. The Lower Permian Insects of Kansas. Part 8. Additional Megasecoptera, Protodonata, Odonata, Homoptera, Psocoptera, Protelytroptera, and Protoperlaria. Proc. American Acad. Arts Sci. $73(3)$ : 29-70.

1964. Studies on North American Carboniferous Insects. 3. A Spilapterid from the Vicinity of Mazon Creek, Illinois (Palaeodictyoptera). Psyche, 71(3): 117-124.

1965. Studies on North American Carboniferous Insects. 4. The Genera Metropator, Eubleptus, Hapaloptera and Hadentomum. Psyche, $72(2): 175-190$.

KuKalová, J.

1969. Revisional Study of the Order Palaeodictyoptera in the Upper Carboniferous Shales of Commentry, France, Part I. Psyche, $76(2): 163-215$.

1969. Ibid., Part II. Psyche, $76(4):$ 439-486.

1970. Ibid., Part III. Psyche, $77(1):$ 1-44.

Lameere, A.

1922. Sur la nervation alaire des insectes. Bull. Classe Sci. Belgique $1922(4)$ : 138-149.

Tillyard, R. J.

1924. Kansas Permian Insects. Part I. The Geologic Occurrence and the Environment of the Insects with Description of a New Palaeodictyopterid. Amer. Journ. Sci., (5) 7: 203-208.

1925. Kansas Permian Insects. Part 4. The Order Palaeodictyoptera. Amer. Journ. Sci., 9 (52) : 328-335. 

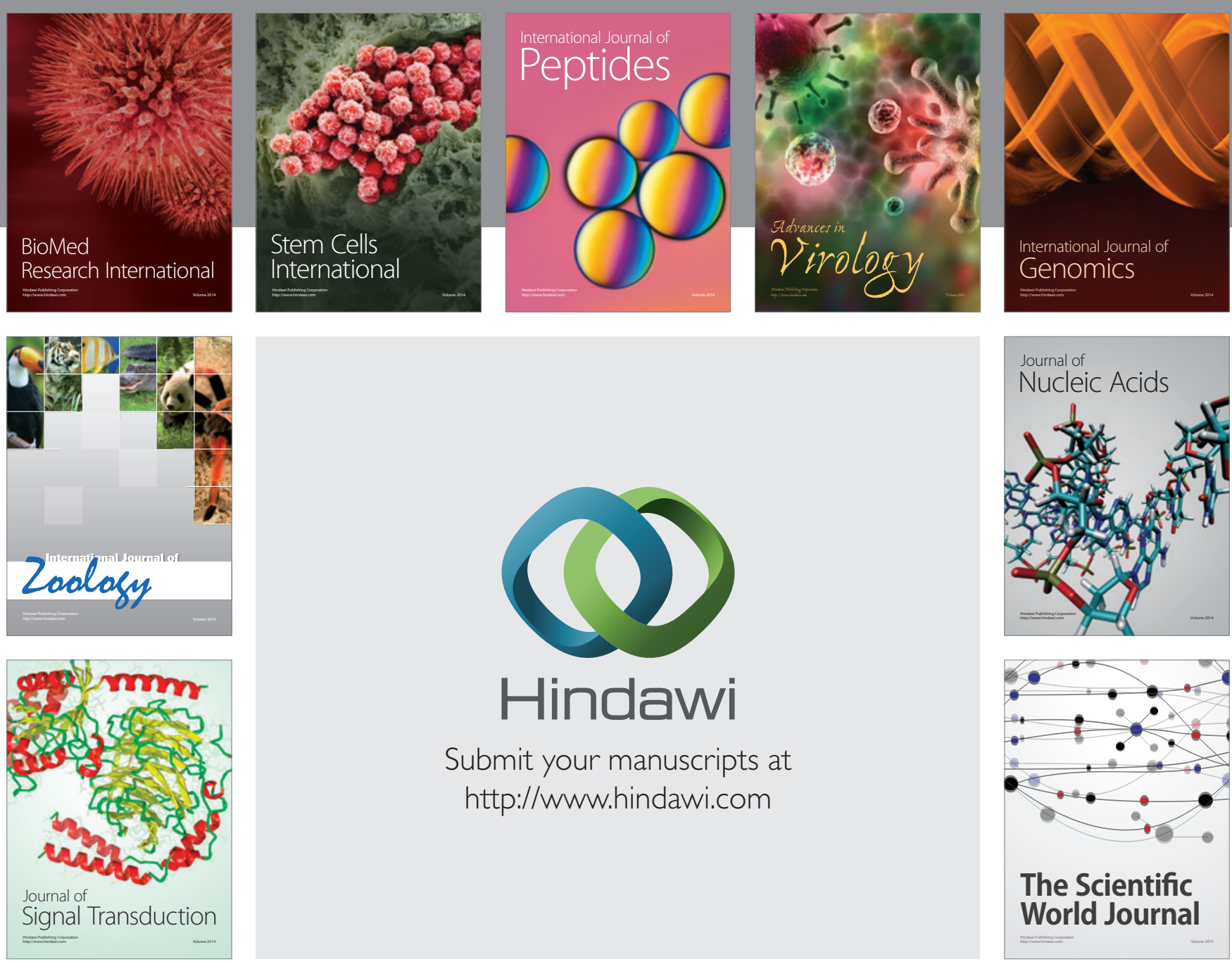

Submit your manuscripts at

http://www.hindawi.com
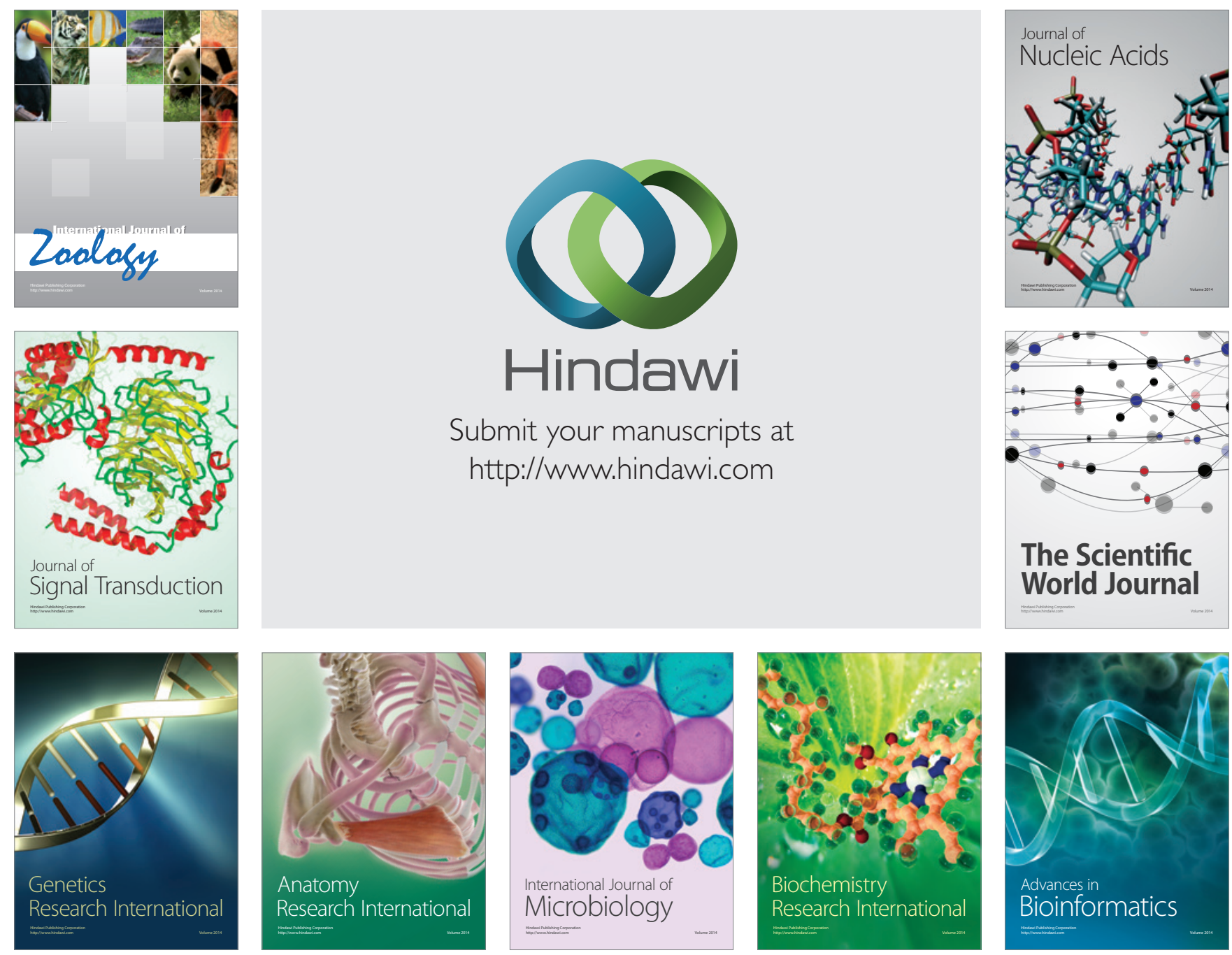

The Scientific World Journal
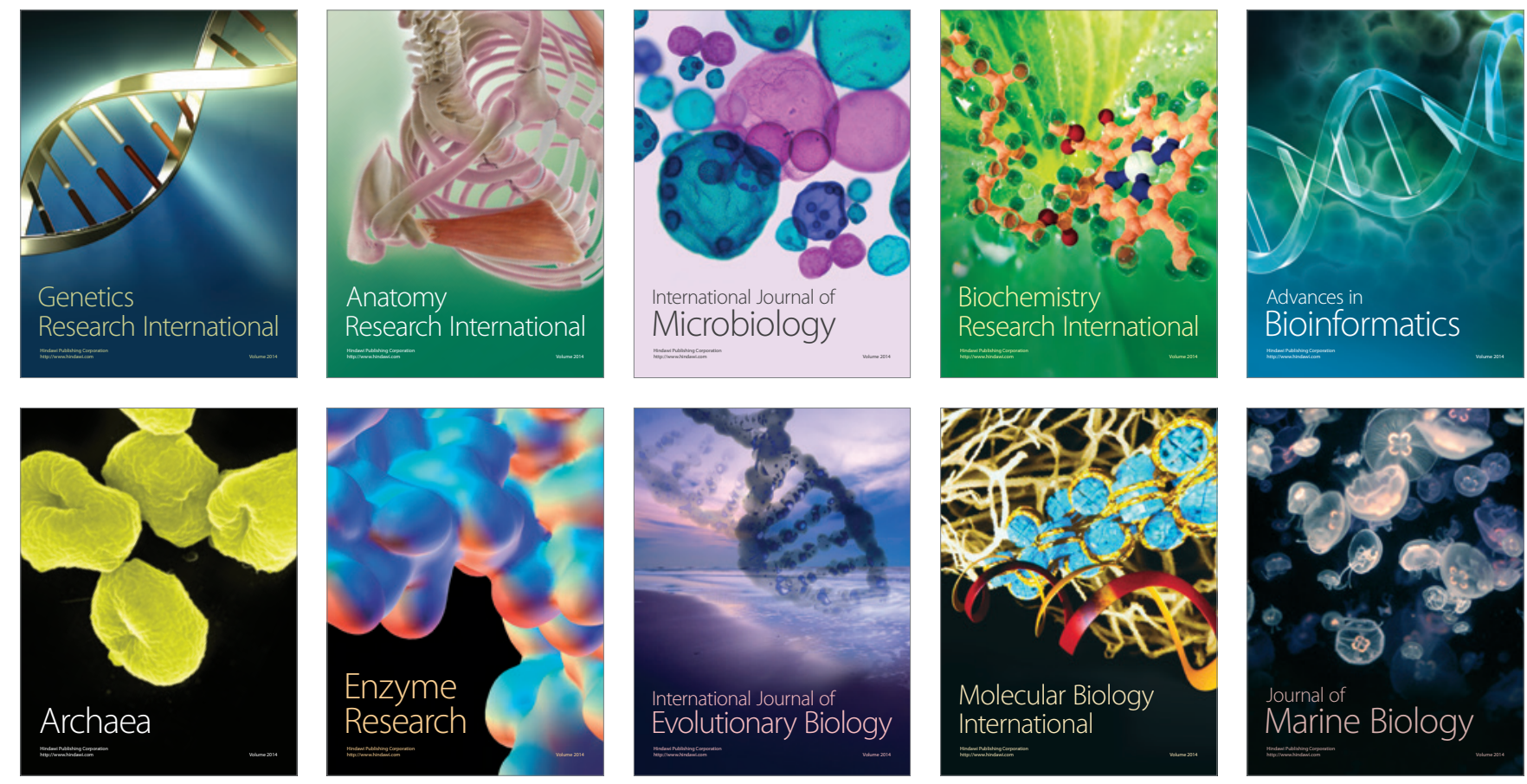